\title{
Percepções dos impactos ambientais da indústria de cerâmica no município de Crato estado do Ceará, Brasil
}

\section{Perceptions of environmental impacts of ceramic industry in the municipality of state Crato Ceará, Brazil}

\author{
Zoraia Úrsula Silva de Alencar-Linard * \\ Ahmad Saeed-Khan ${ }^{* *}$ \\ Patrícia Verônica Pinheiro-Sales Lima**
}

\begin{abstract}
The aim of this study was to analyze the environmental impacts caused by the red ceramic industry, based on the vision of workers and residents in region from Crato - Ceara. Two indexes were calculated: IQA and ISA. The results showed that in the view of respondents the ceramic industry led to degradation. However, these activities were also responsible for creating new jobs.
\end{abstract}

Keywords: Environmental impacts, ceramic industry, sustainable development

Resumo

O objetivo dessa pesquisa foi analisar os impactos socioambientais causados pela indústria cerâmica vermelha, mediante a perspectiva dos trabalhadores e das pessoas residentes no entorno das fábricas. Os índices aplicados nesse estudo, IQA e ISA, demonstraram que as atividades exercidas pela indústria cerâmica levaram à degradação do meio ambiente, na visão dos entrevistados. No entanto, tais atividades também foram responsáveis pela criação de novos empregos.

Palavras-chave: Impacto ambiental, ndústria de cerâmica, desenvolvimento sustentável.

* Rede Municipal de Ensino de Fortaleza-Ceará-Brasil. Correo-e: zoraiaursula@hotmail.com

** Universidade Federal do Ceará-Brasil. Correos-e: saeed@ufc.br, pvpslima@gmail.com 


\section{Introdução}

A atividade industrial tende a agredir o meio ambiente, em especial, quando se utiliza matéria-prima e outros insumos extraídos diretamente da natureza. É o caso da indústria de cerâmica, que tem como matériaprima a argila e como principal insumo energético a lenha. A mineração e o desflorestamento causam impactos sobre o meio físico, biótico e antrópico, provocando mudanças na vida das pessoas que desempenham essas atividades ou residem próximo aos locais de exploração de matériaprima ou de fabricação de produtos cerâmicos (Dias et al., 1999; Sánchez, 2008; Leite e Gonçalves-Fujaco, 2013).

O setor cerâmico é um dos principais consumidores de lenha entre os vários tipos de indústrias que utilizam a biomassa como fonte de energia (Dias et al., 1999). Apesar de seu papel na economia brasileira, o setor cerâmico é bastante pulverizado, composto eminentemente por microempresas, empresas de pequeno e médio porte, com intensiva presença da economia informal. Como agravante, é apontado como um dos principais responsáveis pelo desmatamento do bioma caatinga (Rodrigues et al., 2010).

No ano de 2009, o setor ceramista foi responsável por gerar $10 \mathrm{mil}$ empregos diretos e 40 mil indiretos, no Estado do Ceará, sendo que no ano de 2010, esse setor contava com 420 empresas instaladas em 85 municípios do Estado (FIEC, 2010).

O município do Crato apresenta uma diversidade de recursos naturais e paisagísticos, os quais são explorados de modo a garantir o desenvolvimento de várias atividades econômicas, dentre as quais, a do setor cerâmico, contribuindo, assim, para o desenvolvimento socioeconômico da região. É por dispor de um importante patrimônio ambiental, cultural, científico e histórico que o Município de Crato está inserido no território do Geopark Araripe.

É importante realizar um estudo sistêmico da atividade ceramista para realçar e analisar seus potenciais impactos causados sejam eles positivos e/ou negativos, para que assim sejam tomadas as medidas mitigadoras apropriadas, de modo a garantir a sustentabilidade das indústrias.

Considerando-se o papel da sociedade como agente de transformaçáo e como detentora de meios para a cobrança de atitudes ambientalmente corretas por parte de instituiçóes governamentais e empresas, o objetivo deste estudo foi analisar os impactos socioambientais causados pela indústria de cerâmica vermelha, mediante a perspectiva dos trabalhadores e da comunidade do entorno das fábricas. 


\section{Referencial teórico metodológico}

\subsection{Meio ambiente, impacto socioambiental e a indústria cerâmica}

A Lei 6.938/81, da Política Nacional do Meio Ambiente, no seu art. 3º, inciso I, define meio ambiente como "o conjunto de condiçóes, leis, influências e interações de ordem física, química e biológica, que permite, abriga e rege a vida em todas as suas formas" (MMA, 1981).

O meio ambiente como pauta de discussão nas questóes relacionadas ao desenvolvimento ganhou força em razão da tomada de consciência da população e da propagação do movimento ambientalista (Maimon, 1998). $\mathrm{O}$ cerne dos debates envolve os impactos ambientais resultantes das atividades humanas.

A expressão impacto ambiental, segundo o art. $1^{\circ}$ da Resolução 001/86 do Conselho Nacional do Meio Ambiente (Conama), é [...] qualquer alteração das propriedades físicas, químicas e biológicas do meio ambiente, causada por qualquer forma de matéria ou energia resultante das atividades humanas que, direta ou indiretamente, afetam: a saúde, a segurança e o bem-estar da população; as atividades sociais e econômicas; a biota; as condiçóes estéticas e sanitárias do meio ambiente; a qualidade dos recursos ambientais. (MMA, 1986).

A preocupação com os impactos ambientais provocados pelo uso irracional dos recursos produtivos colocou a indústria como grande responsável por danos à natureza. De fato, até a década de 1970, o comportamento das empresas em relação ao meio ambiente se restringia a corrigir acidentes locais e despoluir, quando evitar os danos deveria ser a meta. Somente a partir da década de 1980, as indústrias começam a mudar de atitude, pondo em prática a responsabilidade socioambiental (Tommasi, 1994).

A literatura aponta a atividade industrial ceramista como uma das principais fontes causadoras de impactos ambientais em áreas rurais do nordeste brasileiro, mais especificamente do bioma local, a caatinga, pelo fato de usar de modo intensivo recursos naturais como a argila e a lenha (Pessoa, 2004; Dias et al., 1999).

A degradação ocasionada por esse tipo de empreendimento é conhecida e os impactos são muitos, começando na área da jazida, compreendendo a extraçáo da matéria-prima propriamente dita e todas as etapas do processo de produçáo, inclusive o tipo, forma de utilização da fonte energética e a geração dos resíduos, até chegar ao transporte final (destino) (Dias et al., 1999).

O desmatamento para consumo de lenha e a exploração da área de extração mineral, podem promover alteraçóes na natureza, na sociedade 
e na economia (Calvão et al., 2013). No âmbito da natureza observamse perda da biodiversidade, remoção e erosão do solo, geração de estéreis, degradação e modificação da paisagem, mudança nas condições das águas superficiais e subterrâneas, poluição do solo, atmosférica e sonora, possível modificação do microclima, modificação das formas de uso do solo, deslocamento da fauna, impacto visual. Já nos âmbitos da sociedade e da economia as alteraçôes estão diretamente relacionadas ao risco à saúde, à qualidade de vida, à geraçâo de emprego e renda (Dias et al., 1999; Sánchez, 2008; Van Gemert et al., 2013).

Nesse contexto, a atividade ceramista apresenta-se como uma potencial ameaça à qualidade do meio ambiente ao mesmo tempo em que consegue gerar renda e emprego para a população pobre e pouco qualificada para o mercado de trabalho, comum nas áreas rurais do nordeste brasileiro. Tal ambiguidade desperta para a necessidade de uma harmonia entre a exploração dos recursos naturais, a proteção do meio ambiente e os interesses econômicos do setor ceramista, objetivando o melhor aproveitamento desses recursos para presentes e futuras geraçóes, ou seja, a sustentabilidade da atividade.

Segundo Leff (2001: 324), "a qualidade de vida depende da qualidade do ambiente para chegar a um desenvolvimento equilibrado e sustentável..." Assim, compreende-se que a sustentabilidade ambiental resulta da influência mútua das condiçôes ecológicas, biológicas, socioculturais e econômicas. Representa uma inter-relação de justiça social, qualidade de vida, equilíbrio ambiental e ruptura com o atual padrão de desenvolvimento (Jacobi, 2003).

Nessa perspectiva, considerou-se no presente estudo que a sustentabilidade ambiental pode ser definida como aquela relacionada à capacidade de suporte dos ecossistemas para absorver ou se recuperar das agressóes derivadas da ação humana, implicando um equilíbrio entre as taxas de emissão e/ou produção de resíduos e as taxas de absorção e/ou regeneração da base natural de recursos (Guimarães, 1997 apud Rodrigues, 2006).

\subsection{A indústria cerâmica no Brasil e no Estado do Ceará}

A maior concentração de indústrias de todos os segmentos cerâmicos se localiza, no Brasil, nas regióes Sudeste, Sul e Nordeste (mME, 2010). No universo da atividade industrial, o setor de cerâmica vermelha (ou estrutural) se destaca por ser um dos que mais absorve mão de obra. Este setor, no ano 2009, foi o responsável pela criação de 293 mil empregos (MME, 2010). De acordo com os mesmos dados o Brasil, no ano de 2009, tinha cerca de 7.400 empresas cerâmicas, as quais tiveram um faturamento de R \$ 7 bilhóes (MME, 2010). 
O setor cerâmico é bastante diversificado em relação aos tipos de produtos fabricados, podendo ser classificado, segundo a Associação Brasileira de Cerâmica, nos segmentos: cerâmica vermelha (ou estrutural); cerâmica branca; materiais de revestimento; materiais refratários; isolantes térmicos; fritas e corantes; abrasivos; vidro, cimento e cal; cerâmica de alta tecnologia/cerâmica avançada (ABC, 2011).

De acordo com a Federação das Indústrias do Estado do Ceará (FIEC), no ano de 2010, o setor ceramista era constituído por 420 empresas instaladas em 85 municípios cearenses, responsáveis por movimentar cerca de $\mathrm{R} \$ 185.5$ milhóes no ano de 2009 , representando crescimento de 13\% em relação a 2008 (FIEC, 2010). Esse setor foi, no dito ano, responsável por oferecer dez mil empregos diretos e 40 mil indiretos, com expectativas de aumento.

Segundo o IEL-CE/2002 as maiores concentrações de mão de obra do setor cerâmico no Ceará estão em dez Municípios, dentre eles o Crato. Os Municípios que apresentaram maior absorção de mão de obra foram Russas, Caucaia, Maracanaú, Sobral, Aquiraz, Limoeiro do Norte e Crato, que representaram juntos, $57.3 \%$ do total de máo de obra ocupado (FIEC, 2005).

Os principais produtos fabricados pela indústria de cerâmica vermelha do Crato são tijolos de tamanhos variados e telhas de tipos diversos, além de lajota e revestimento para paredes, estes em menor quantidade. Além dos produtos de queima vermelha, também se fabricam em pequena escala cerâmica branca e mesclada as quais constituem a matéria-prima para a fabricação dos artefatos de queima branca oriunda de outros Estados do Nordeste.

\section{Metodologia}

Neste estudo foram analisadas quatro indústrias de cerâmicas vermelhas as quais correspondem a $40 \%$ do total das indústrias do município. Foram entrevistados 97 trabalhadores da indústria cerâmica, selecionados em diferentes atividades e 68 moradores residentes no entorno onde as atividades se desenvolvem.

Para avaliar a qualidade ambiental e a sustentabilidade do setor cerâmico, optou-se pela escolha de indicadores que de alguma maneira influenciam nos elementos fundamentais da natureza, ou seja, ar, solo, água e cobertura vegetal, considerando indicadores de Pressão, de Estado e de Resposta-PER (OECD, 2001). Estes indicadores foram agregados e transformados no Índice de Qualidade Ambiental (IQA) e no Índice de Sustentabilidade Ambiental (ISA) da área do estudo. A escolha foi baseada no sistema de indicadores ambientais proposto pela Organization for Econo- 
mic Cooperation and Development, oECD (oECD, 2008). A avaliação da qualidade ambiental, com uso de indicadores ambientais, permite avaliar a qualidade do meio ambiente na área de estudo.

O cálculo dos índices de qualidade ambiental e de sustentabilidade ambiental adotou a mesma expressão matemática:

$$
\text { Índice }=\frac{1}{S} \cdot \sum_{I=1}^{S} C_{1}
$$

Sendo:

$$
C_{l}=\frac{1}{m} \cdot \sum_{j=1}^{m}\left[\frac{1}{n} \cdot \sum_{i=1}^{n}\left(\frac{E_{j}}{E_{\max _{i}}}\right)\right]
$$

Em que:

Indice = Índice de Qualidade Ambiental (IQA) ou Índice de Sustentabilidade Ambiental (ISA)

$S=$ número de indicadores que compóem o Índice de Qualidade Ambiental ou Índice de Sustentabilidade Ambiental.

$C_{l}=$ contribuição do indicador "l" no Índice de Qualidade Ambiental ou no Índice de Sustentabilidade Ambiental.

$\mathrm{m}=$ número de entrevistados

$E i j=$ escore da $i$-ésima variável do indicador “ $P$ ” obtido pela $j$-ésimo entrevistado;

$E \max i=$ escore máximo da $i$-ésima variável do indicador " $l$ ";

$\mathrm{n}$ = número de variáveis que compóem o indicador " $P$ ";

No cálculo do IQA foram adotados dois indicadores $(l=2)$, compostos por 15 variáveis distribuídas conforme quadro 1.

\section{Quadro 1}

Distribuiçáo e escore das variáveis do índice de qualidade

\begin{tabular}{|c|c|c|c|}
\hline \multirow{2}{*}{ Indicador } & \multirow{2}{*}{ Variável } & \multicolumn{2}{|c|}{$\begin{array}{c}\text { Escore atribuido à i-ésima } \\
\text { variável }\end{array}$} \\
\hline & & $\begin{array}{l}\text { Resposta } \\
\text { SIM }\end{array}$ & Resposta NÃO \\
\hline \multirow{5}{*}{$\begin{array}{l}\text { Mudanças na } \\
\text { área do estudo }\end{array}$} & $\begin{array}{l}\text { - A paisagem foi modificada em razão da } \\
\text { retirada da vegetaçáo e do solo por conta } \\
\text { da mineraçáa }\end{array}$ & 0 & 1 \\
\hline & - O desaparecimento de espécies animais & 0 & 1 \\
\hline & - O desaparecimento de plantas da regiáo & 0 & 1 \\
\hline & - Aumento da poluição atmosférica & 0 & 1 \\
\hline & - Aumentou no número de residências & 0 & 1 \\
\hline
\end{tabular}
ambiental da área do estudo 


\begin{tabular}{|c|c|c|c|}
\hline \multirow{2}{*}{ Indicador } & \multirow{2}{*}{ Variável } & \multicolumn{2}{|c|}{$\begin{array}{c}\text { Escore atribuido à i-ésima } \\
\text { variável }\end{array}$} \\
\hline & & $\begin{array}{l}\text { Resposta } \\
\text { SIM }\end{array}$ & Resposta NẪO \\
\hline \multirow{10}{*}{$\begin{array}{l}\text { Impactos causa- } \\
\text { dos pela indús- } \\
\text { tria cerâmica }\end{array}$} & - Prejuízo às áreas destinadas à pecuária & 0 & 1 \\
\hline & - Prejuízo às áreas destinadas à lavoura & 0 & 1 \\
\hline & - Promover a poluição do ar & 0 & 1 \\
\hline & - Degradar o meio ambiente & 0 & 1 \\
\hline & $\begin{array}{l}\text { - Mudar a paisagem natural em virtude } \\
\text { da retirada da vegetaçáo e do solo para } \\
\text { produçáo }\end{array}$ & 0 & 1 \\
\hline & $\begin{array}{l}\text { - Promover a erosão do solo em decorrên- } \\
\text { cia da mineraçáo }\end{array}$ & 0 & 1 \\
\hline & $\begin{array}{l}\text { - O desaparecimento de espécies animais } \\
\text { da área }\end{array}$ & 0 & 1 \\
\hline & $\begin{array}{l}\text { - O desaparecimento de espécies vegetais } \\
\text { (plantas) da área }\end{array}$ & 0 & 1 \\
\hline & $\begin{array}{l}\text { - Elevar a temperatura da região pela } \\
\text { emissáo de gases e o desmatamento }\end{array}$ & 0 & 1 \\
\hline & $\begin{array}{l}\text { - Aumentar o número de doenças respi- } \\
\text { ratórias }\end{array}$ & 0 & 1 \\
\hline
\end{tabular}

Fonte: elaboração própria.

O IQs é resultado da agregaçáo de oito indicadores $(\mathrm{l}=8)$, representando 32 variáveis distribuídas conforme quadro2.

\section{Quadro 2 \\ Distribuição e escore das variáveis do índice de sustentabilidade ambiental das cerâmicas de Crato-CE}

\begin{tabular}{|c|c|c|c|}
\hline \multirow{2}{*}{ Indicador } & \multirow{2}{*}{ Variável } & \multicolumn{2}{|c|}{$\begin{array}{l}\text { Escore atribuido à } \\
\text { i-ésima variável }\end{array}$} \\
\hline & & $\begin{array}{l}\text { Resposta } \\
\text { SIM }\end{array}$ & $\begin{array}{l}\text { Resposta } \\
N \tilde{A O}\end{array}$ \\
\hline \multirow{3}{*}{$\begin{array}{l}\text { Projetos de } \\
\text { Educaçáo } \\
\text { ambiental } \\
\text { e social }\end{array}$} & $\begin{array}{l}\text { - Projeto de educação ambiental para traba- } \\
\text { lhadores }\end{array}$ & 1 & 0 \\
\hline & $\begin{array}{l}\text { - Projeto de educação ambiental para comu- } \\
\text { nidades }\end{array}$ & 1 & 0 \\
\hline & - Realiza ou financia projeto social & 1 & 0 \\
\hline
\end{tabular}


Continuación...

\begin{tabular}{|c|c|c|c|}
\hline \multirow{2}{*}{ Indicador } & \multirow{2}{*}{ Variável } & \multicolumn{2}{|c|}{$\begin{array}{l}\text { Escore atribuido à } \\
\text { i-ésima variável }\end{array}$} \\
\hline & & $\begin{array}{l}\text { Resposta } \\
\text { SIM }\end{array}$ & $\begin{array}{l}\text { Resposta } \\
N A \bar{O}\end{array}$ \\
\hline \multirow{12}{*}{$\begin{array}{l}\text { Fontes } \\
\text { energéticas }\end{array}$} & - Lenha de manejo florestal & 1 & 0 \\
\hline & - Poda do cajueiro & 1 & 0 \\
\hline & - Restos da indústria de móveis & 1 & 0 \\
\hline & - Bagaço de cana de açúcar & 1 & 0 \\
\hline & - Casca de coco babaçu & 1 & 0 \\
\hline & - Casca de pequi & 1 & 0 \\
\hline & - Poda de árvore da cidade do Crato & 1 & 0 \\
\hline & - Serragem de madeira & 1 & 0 \\
\hline & - Usa apenas lenha de manejo florestal & 1 & 0 \\
\hline & - Usa apenas outro tipo de fonte energética & 1 & 0 \\
\hline & - Usa mais de um tipo de fonte energética & 1 & 0 \\
\hline & - Aguação & 1 & 0 \\
\hline \multirow{5}{*}{$\begin{array}{l}\text { Medidas de } \\
\text { reduçáo da } \\
\text { poluiçáo } \\
\text { atmosférica } \\
\text { (produçáa } \\
\text { e lavra) }\end{array}$} & $\begin{array}{l}\text { - Usa filtro nas chaminés ou fornos adaptados } \\
\text { com filtros }\end{array}$ & 1 & 0 \\
\hline & - Manutenção periódica dos caminhões & 1 & 0 \\
\hline & - Manutenção periódica das máquinas & 1 & 0 \\
\hline & - Barreira verde & 1 & 0 \\
\hline & - O transporte da argila é feito coberto com lona & 1 & 0 \\
\hline \multirow{2}{*}{$\begin{array}{l}\text { Medidas de } \\
\text { prevençãa da } \\
\text { poluição do solo } \\
\text { (área de lavra) }\end{array}$} & $\begin{array}{l}\text { - Abastecimento dos caminhôes fora da área } \\
\text { de extraçáo mineral }\end{array}$ & 1 & 0 \\
\hline & $\begin{array}{l}\text { - Manutençáo de máquinas, caminhóes e equi- } \\
\text { pamentos fora da área de extração mineral }\end{array}$ & 1 & 0 \\
\hline $\begin{array}{l}\text { Medidas de } \\
\text { redução da }\end{array}$ & - Uso de abafadores nos equipamentos & 1 & 0 \\
\hline $\begin{array}{l}\text { poluiçãa sonora } \\
\text { (produção e lavra) }\end{array}$ & - Manutenção periódica das máquinas & 1 & 0 \\
\hline \multirow{5}{*}{$\begin{array}{l}\text { Reutilização } \\
\text { dos resíduos da } \\
\text { produçáo e } \\
\text { rejeito da } \\
\text { mineração }\end{array}$} & - Reincorporados ao processo produtivo & 1 & 0 \\
\hline & - Pavimentar áreas de extração mineral & 1 & 0 \\
\hline & - Pavimentar áreas ao redor das cerâmicas & 1 & 0 \\
\hline & $\begin{array}{l}\text { - Usado pela Prefeitura e Estado para aplainar } \\
\text { estradas carroçáveis }\end{array}$ & 1 & 0 \\
\hline & - Aplainar terrenos da área de lavra & 1 & 0 \\
\hline $\begin{array}{l}\text { Destino do } \\
\text { estéril/restolho do } \\
\text { desmatamento } \\
\text { da área de lavra }\end{array}$ & $\begin{array}{l}\text { - Estocado próximo à área de lavra para recu- } \\
\text { perá-la }\end{array}$ & 1 & 0 \\
\hline $\begin{array}{l}\text { Medidas de } \\
\text { recuperaçáo da }\end{array}$ & - Aplainamento da superfície e reflorestamento & 1 & 0 \\
\hline $\begin{array}{l}\text { área de lavra } \\
\text { parada em } \\
\text { definitivo }\end{array}$ & $\begin{array}{l}\text { - O reflorestamento é feito com espécies na- } \\
\text { tivas }\end{array}$ & 1 & 0 \\
\hline
\end{tabular}

Fonte: elaboraçấo própria. 
O IQA e o ISA variam de 0 a 1 e seguem a parametrização utilizada pela ONU para O IDH (PNUD, 2005).

Para O IQA:

a) Baixa qualidade ambiental

$0 \leq \mathrm{IQA} \leq 0,5$

b) Média qualidade ambiental

$0,5<\mathrm{IQA} \leq 0,8$

c) Alta qualidade ambiental

$0,8<\mathrm{IQA} \leq 1$

Para O ISA:

a) Sustentabilidade ambiental baixa

$0 \leq \mathrm{ISA} \leq 0,5$

b) Sustentabilidade ambiental média

$0,5<$ ISA $\leq 0,8$

c) Sustentabilidade ambiental alta

$0,8<$ ISA $\leq 1$

\section{Resultados}

\subsection{Aspectos gerais da indústria de cerâmica vermelha de Crato-Ce}

Pode-se constatar que todas as indústrias participantes da pesquisa estão edificadas em terras particulares, sendo essas gerenciadas pelos próprios donos e membros da família. As indústrias encontram-se próximas das jazidas de exploração de matéria-prima (distâncias aproximadas entre as empresas e as jazidas: entre $200 \mathrm{~m}$ e $3.5 \mathrm{~km}$ ), características comuns entre as indústrias cerâmicas do Nordeste, consoante observam (Amaral Filho e Coelho, 2006).

Quanto à estrutura do ambiente de trabalho, as empresas apresentam, em geral, condições razoáveis de conforto, exceto em uma fábrica. As fábricas apresentam galpóes cobertos nos quais são guardadas as máquinas e alguns fornos, além de servir de local para secar as peças e/ou armazenar material. Duas fábricas possuem refeitórios com certa estrutura e organização (cantina, mesas, bancos, bebedouro e ambiente higienizado).

\subsection{Geraçáo de emprego e renda}

As quatro empresas relacionadas, três empresas de pequeno porte e uma de médio porte, geraram até outubro de 2010 o equivalente a 345 empregos diretos, e são empreendimentos em expansão no Município do Crato. Elas estão inseridas em um setor -o cerâmico- carente de mão de obra qualificada, sendo comum a oscilação no número de trabalhadores e a rotatividade de pessoal.

Quanto à política salarial, os empresários remuneravam os trabalhadores com 1 (um) salário mínimo ou mais (tabela 1). Cinquenta por cento das indústrias funcionam com 44 horas semanais e, a outra metade, com 48 horas semanais, de segunda a sábado. 
Tabela 1

Distribuiçáo absoluta e relativa dos trabalhadores da indústria de cerâmica entrevistados, segundo a renda mensal (2010)

\begin{tabular}{lccc}
\hline $\begin{array}{c}\text { Renda dos trabalhadores } \\
\text { da indústria (salário } \\
\text { minimo em } R \$ \text { ) }\end{array}$ & $\begin{array}{c}\text { Frequência } \\
\text { absoluta }\end{array}$ & $\begin{array}{c}\text { Frequência } \\
\text { relativa (\%) }\end{array}$ & $\begin{array}{c}\text { Percentual } \\
\text { acumulado }\end{array}$ \\
\hline 545 & 57 & 58,76 & 58,76 \\
546 a 1.090 & 35 & 36,08 & 94,84 \\
1.090 a 1.635 & 2 & 2,07 & 96,91 \\
1.636 a 2.180 & 3 & 3,09 & 100 \\
Total & 97 & 100 & \\
\hline
\end{tabular}

Fonte: elaboração própria com dados da pesquisa.

Constatou-se que o valor mínimo pago aos trabalhadores era de um salário mínimo ( $R$ \$ 545.00) e o valor máximo era de $R$ \$2,180.00 em 2010. A maioria dos trabalhadores (59\%) recebia um salário mínimo e somente 5\% tinha remuneração acima de dois salários.

Essas indústrias empregam pessoas do Crato e de outros municípios da regiáo do Cariri. A pesquisa revelou que a maioria dos trabalhadores (64.9\%) reside nas comunidades onde as cerâmicas estão instaladas ou em localidades circunvizinhas. A quantidade restante de trabalhadores reside na cidade de Crato (28.9\%) e em outras cidades (6.2\%), distantes aproximadamente $26 \mathrm{~km}$ e $47 \mathrm{~km}$, respectivamente. Com base nos dados se pode dizer que a indústria cerâmica contribui para a geração de emprego e renda às comunidades do entorno.

A idade dos trabalhadores varia de 18 anos a 69 anos. A maioria, com menos de 40 anos de idade, levando a crer que a predominância de pessoas com essa média de idade nesse setor decorre da resistência física que o trabalho exige.

A realidade educacional dos trabalhadores da indústria cerâmica de Crato não é diferente das outras atividades rurais no Ceará. Observou-se que 64\% dos entrevistados não sabiam ler nem escrever ou eram analfabetos funcionais, só lêem e escrevem, tendo no máximo 4 anos de escolaridade. Tal fato representa um índice muito elevado de baixa escolaridade, quando comparados os diversos níveis de modalidades de ensino, como a Educação de Jovens e Adultos (EJA), e os investimentos em educação no país na última década.

A presença feminina na indústria cerâmica cratense se restringia, até entấo, ao serviço burocrático, de escritório. Um aspecto que chamou a atenção foi a presença da mulher no setor de produção de cerâmica. 
Constava do quadro de funcionários de uma das fábricas o total de 11 mulheres atuando no setor de produção nas mais variadas funções.

Dentre outras adequaçóes, as empresas participantes do estudo buscavam atender às recomendaçóes previstas na CLT, normas reguladoras (NR) e legislação ambiental. Nesse sentido, verificou-se a existência do Programa de Controle Médico de Saúde Ocupacional (pCMso) em todas as empresas.

Em relação à área de segurança do trabalhador, foi constatada em apenas uma empresa a existência de Comissão Interna de Prevenção de Acidentes (CIPA), assim como o Serviço Especializado em Engenharia de Segurança e em Medicina do Trabalho (Sesmt).

Quanto aos equipamentos de proteção individual (EPI), todas as empresas disponibilizavam, para os operários. Aventou-se, porém, a ideia de que, embora se faça um trabalho de fiscalização e conscientização sobre a importância do uso destes para a vida do trabalhador, esses equipamentos não são usados por todos, e aqueles que os utilizam não o fazem por todo o tempo de desempenho das atividades. Tal fato, comprovado nas visitas a campo, fere as obrigaçóes do trabalhador em relação ao uso dos EPIs, segundo a NR6/78.

A matéria-prima (argila), usada para fabricação das peças de cerâmica vermelha, é originada de rochas sedimentares e extraída da própria área onde as unidades fabris estão instaladas, sendo também procedente de áreas próximas onde se encontram essas unidades. Das empresas entrevistadas, $75 \%$ possuem jazidas próprias e têm plano de lavra. Apenas uma empresa, 25\%, adquire matéria-prima de terceiros.

A lavra realizada pelo setor cerâmico no referido Município é feita a céu aberto, sendo a maquinaria básica utilizada: escavadeiras e pás mecânicas, popularmente conhecidas por enchedeiras; e o transporte da argila é feito por meio de caminhóes-caçamba, havendo pouca participação humana nesse processo.

Vale ressaltar que todas as indústrias cerâmicas possuíam processos produtivos semiautomáticos e que em todas as etapas há geração de resíduos.

Observou-se que havia certa uniformidade das empresas no que se refere ao padrão tecnológico, sendo que apenas uma apresentava diferenças, equipamentos e maquinários menos modernos, em relação às outras. Das indústrias envolvidas no estudo, 100\% delas têm como base da produção tijolos de vários tamanhos e telhas de tipos diversos, que juntos representam $72.8 \%$ do total dos produtos por elas fabricados. Algumas unidades produzem lajota e revestimento para parede. $\mathrm{O}$ percentual dos produtos fabricados pelas quatro empresas é o seguinte: $36.4 \%$ correspondem a tijolos, $36.4 \%$ a telhas, $18.2 \%$ a lajotas e $9 \%$ a revestimentos. 
No passado, além da lenha, os produtos derivados do petróleo eram usados para alimentar os fornos da indústria cerâmica de Crato, sendo aqueles emissores de gases poluentes para a atmosfera. Iniciou-se, na década passada, mudança na matriz energética e atualmente, as indústrias pesquisadas têm como base energética a biomassa.

A atividade ceramista está entre aquelas em que ainda há o predomínio do uso da lenha, realidade citada por (Nascimento, 2007; Dias et al., 1999; Pessoa, 2004; Mme, 2010; Narasimha e Nagesha, 2013) e constatada neste estudo, conforme gráfico 1 . O combustível mais utilizado pelas indústrias participantes da pesquisa é a madeira, tradicionalmente chamada de lenha, no caso, a lenha de reflorestamento (31\%). Esse aumento no uso de lenha de manejo florestal vai ao encontro do que aponta o Anuário Estatístico do Setor de Transformação de Não-Metálico sobre a tendência no aumento do uso desse insumo como forma de garantir a sustentabilidade energética, segundo (MME, 2010).

\section{Gráfico I \\ Distribuiçáo relativa dos tipos de insumos energéticos utilizados pelas cerâmicas de Crato (2010)}

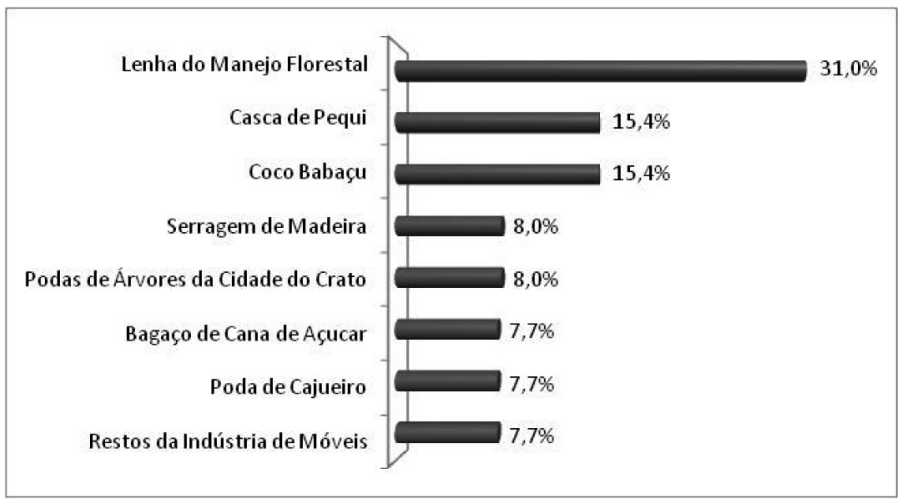

Fonte: elaboração própria com dados da pesquisa (2010).

Três indústrias (das quatro pesquisadas) utilizavam mais de dois tipos diferentes de insumos no processo de queima, enquanto uma delas fazia uso somente da lenha. Embora todos os empresários participantes do estudo tenham afirmado usar "madeira legal", oriunda de Plano de Manejo Florestal Sustentável (PMFs) previsto no Código Florestal Brasileiro de 1965, somente três empresas possuíam o PMFs, e uma indústria empregava lenha de manejo oriunda de áreas de terceiros. No geral, 25\% do total das indústrias utilizavam, somente, lenha de manejo procedente de área própria; $50 \%$ usavam parte de área própria e outra de terceiros e $25 \%$, somente, de origem de áreas de terceiros. 
Os insumos energéticos utilizados pela indústria cerâmica cratense são oriundos de municípios da regiáo do Cariri (37.5\%), de outras regióes do Estado do Ceará (25\%) e dos Estados de Pernambuco e Piauí (37.5\%).

O cenário existente no Crato aponta a indústria cerâmica como um setor com potencial elevado de degradaçáo ambiental, apesar da sua importância como geradora de emprego e renda para a população mais pobre. Tal potencial é percebido pelos moradores das comunidades onde as fábricas estão instaladas e, também, de seus trabalhadores.

\subsection{Percepçáo dos impactos causados pela atividade de mineraçáo e pelo processo produtivo}

Acredita-se que a percepção ambiental é uma aliada nas questôes referentes à conservação e preservação dos recursos naturais (Gifford, 2014). Os indivíduos como sujeitos da sociedade ao perceberem os riscos aos quais encontram-se expostos tendem a ser sensibilizados e assim, tornam-se mais propensos a contribuir para a sustentabilidade dos ecossistemas.

No contexto da indústria cerâmica do Crato, espera-se que a percepção quanto aos seus impactos ambientais seja um fator de promoção de sustentabilidade da atividade. É importante ressaltar, no entanto, que a percepçáo dos entrevistados quanto aos impactos ambientais não implica necessariamente em ocorrência do problema. Porém, se por um lado tal percepção é resultado de uma opinião individual influenciada por fatores subjetivos e na maioria das vezes não passíveis de mensuração, por outro, reflete o desconforto de uma população que sente-se atingida pelas atividades da indústria cerâmica.

Os dados da tabela 2 apresentam a percepção dos moradores das comunidades onde as fábricas estão instaladas e, também, dos seus trabalhadores, quanto aos impactos causados pelas atividades de mineração e pelo processo produtivo. $\mathrm{Na}$ tabela foram destacados apenas os impactos negativos, embora sejam percebidos impactos positivos como a geração de emprego e renda já citados.

A descaracterização da paisagem natural (modificação da paisagem), o aumento da poluição atmosférica, o aumento da temperatura local e a degradação do meio ambiente foram percebidos com maior frequência pelos entrevistados. Na visão desses, o desmatamento das áreas destinadas à mineração, e a própria mineração, modificaram a paisagem e contribuíram, juntamente com os gases emitidos pelas chaminés das cerâmicas, para elevar a temperatura da regiáo onde estão localizadas.

A erosão do solo, a redução e/ou desaparecimento de espécies animais e vegetais são impactos citados de forma recorrente na literatura (Dias 


\section{Tabela 2}

\section{Distribuição absoluta e relativa dos moradores e trabalhadores entrevistados, segundo a percepçáo sobre os impactos negativos gerados pela indústria cerâmica de Crato-CE (2010)}

\begin{tabular}{|c|c|c|}
\hline Impactos negativos da induistria cerâmica & $\begin{array}{c}\text { Frequência } \\
\text { absoluta }\end{array}$ & Percentual* \\
\hline Prejuízos à pecuária & 27 & 16 \\
\hline Redução ou desaparecimento de espécies vegetais da área & 51 & 31 \\
\hline Prejuízos à lavoura & 53 & 32 \\
\hline Redução ou desaparecimento de espécies animais da área & 57 & 35 \\
\hline Aumento do número de doenças respiratórias & 68 & 41 \\
\hline Promoção da erosão do solo em decorrência da mineração & 72 & 44 \\
\hline Degradação do meio ambiente & 76 & 46 \\
\hline $\begin{array}{l}\text { Aumento da temperatura (desmatamento e gases das } \\
\text { chaminés) }\end{array}$ & 78 & 47 \\
\hline Aumento da poluição atmosférica & 100 & 61 \\
\hline Descaracterização da paisagem natural & 107 & 65 \\
\hline Total de entrevistados & 165 & 100 \\
\hline
\end{tabular}

et al., 1999; Sánchez, 2008). Na percepção dos entrevistados houve diminuição e/ou desaparecimento de espécies animais e vegetais da região. Considerando-se que o objetivo desse estudo não é a mensuração ou constatação dos impactos reais da indústria cerâmica, mas sim, a percepção da população em relação a esses; é importante enfatizar que o desaparecimento de espécies animais da região, o aumento da temperatura local e demais impactos apontados pelos entrevistados não foram constatados empiricamente e, portanto, podem náo representar a realidade. Além disso, sabe-se que não se restringem à realização da atividade cerâmica, porque outros fatores também podem contribuir para tal, como o desmatamento e a emissão de gases por parte de outras atividades humanas e industriais como a agropecuária e a caça predatória (Rodriguez e Perez, 2013).

No entanto, os entrevistados apresentaram alguns argumentos para justificar suas respostas. Os 32\% que disseram ser a atividade ceramista responsável por causar prejuízos à lavoura relataram que as pessoas preferem trabalhar nas cerâmicas em vez da agricultura, por terem a garantia de uma renda, que é incerta na agricultura; que as áreas de plantio foram substi- 
tuídas pela exploração mineral, o que contribuiu para o empobrecimento do solo, o que dificulta o desenvolvimento das culturas ali cultivadas.

Ainda segundo relatos, foram despendidos esforços com vistas a reduzir os impactos da emissão dos gases oriundos do processo de queima na secagem das peças (melhorando a eficiência térmica dos fornos mediante o uso de filtros) e também diminuir o consumo de lenha (por meio da introdução de outros tipos de insumos energéticos). No entanto, observaçôes feitas in loco e a constatação por meios das entrevistas demonstraram que, apesar da fumaça emitida pelas chaminés e da poeira decorrente do processo de mineração, mencionadas como impactos presentes na área, estas foram apontadas como sem efeitos diretos sobre as pessoas das comunidades.

Porém, mesmo sem considerar que a poeira e a fumaça atingem diretamente as comunidades, as mesmas foram associadas pelos entrevistados, aos fatores que contribuem para o aumento das doenças respiratórias, demonstrando que, em última análise representam uma consequência direta da atividade ceramista sobre a população.

A análise da percepção dos entrevistados quanto aos impactos ambientais da indústria cerâmica considera, por fim, que os indivíduos diferem em sua percepção em consequência de um conjunto de fatores que moldam a visão de cada um: características sociais (sexo, idade, escolaridade, classe social), experiências pessoais, bases conceituais adquiridas, aspectos culturais. No entanto, as diferenças individuais não são suficientes para invalidar o resultado geral de que os indivíduos entrevistados conseguem perceber possíveis danos causados pela atividade.

\subsection{Os indicadores $e$ indices}

O nível da qualidade ambiental da área no entorno das indústrias de cerâmicas, na percepçáo dos entrevistados, foi analisado a partir do Índice de Qualidade Ambiental. O IQAreflete tão somente o julgamento dos entrevistados, o que pode ou náo representar as verdadeiras condiçóes ambientais da área de estudo.

O resultado do IQA permitiu considerar que, na percepçáo dos entrevistados, a qualidade ambiental da área é baixa, pois o resultado 0.48 (tabela 3).

O baixo valor do IQA decorre da poluição atmosférica, degradação do meio ambiente e modificação da paisagem natural, na opinião dos trabalhadores e moradores das comunidades entrevistados.

Apesar de retratar um descontentamento dos entrevistados em relação à industria cerâmica, o baixo IQA pode ser um alerta para a necessidade de mudanças no setor de modo a torná-lo mais sustentável. 


\section{Tabela 3}

Índice de Qualidade Ambiental (IQA) e contribuiçóes dos indicadores para o IQA da área do estudo, Crato-CE (2010)

\begin{tabular}{lcc}
\hline \multicolumn{1}{c}{ Indicadores } & Valor do indicador & $\begin{array}{c}\text { Contribuiçóes do } \\
\text { indicador para IQA (\%) }\end{array}$ \\
\hline Mudanças na área do estudo & 0,49 & 52,01 \\
Impactos da indústria cerâmica & 0,46 & 47,99 \\
Índice de Qualidade Ambiental & \multicolumn{2}{c}{0,48} \\
\hline
\end{tabular}

Fonte: elaboração própria com dados da pesquisa (2010).

Como se observa na tabela 4, as empresas cerâmicas apresentaram nível de sustentabilidade médio, pois o resultado do índice final foi 0,71. Apenas uma cerâmica (D), das quatro entrevistadas, apresentou baixo índice de sustentabilidade ambiental. Seu desempenho se pode atribuir, em parte, ao fato de ela não dispor de área para realizar extração mineral. Desta maneira, para evitar a subestimação do índice de sustentabilidade ambiental, foi usado o valor (0.5) para os indicadores de medidas de prevenção da poluição do solo, de recuperação da área de lavra parada e do destino do estéril/ restolho do desmatamento da área de lavra dessa empresa.

O índice de sustentabilidade ambiental das cerâmicas recebeu maiores contribuições dos indicadores de redução da poluição, sonora e atmosférica, seguido dos indicadores de destino do estéril do desmatamento, das medidas de recuperaçáo da área de lavra e de utilização dos resíduos.

Apesar de as fábricas utilizarem biomassa como fonte energética, o uso da lenha predomina nessa atividade (embora de reflorestamento), o que fez com que o indicador de fontes de energias tivesse baixa contribuição na formação do índice, assim como o indicador de projetos. Investe-se em projetos sociais, porém, em relação à Educação Ambiental, nada é feito.

O índice de sustentabilidade ambiental mostrou que o setor cerâmico de Crato, ainda que timidamente, está se preocupando com o meio ambiente e investindo em técnicas, tecnologias e práticas que previnam el ou minimizem os impactos de diferentes naturezas, sobretudo ambientais.

É importante ressaltar que apesar de os resultados se mostrarem de certa forma satisfatórios não se deve perder de vista a necessidade de melhorias progressivas, corrigindo as deficiências que ainda permanecem como entraves para o alcance da sustentabilidade ambiental em meio ao setor. 


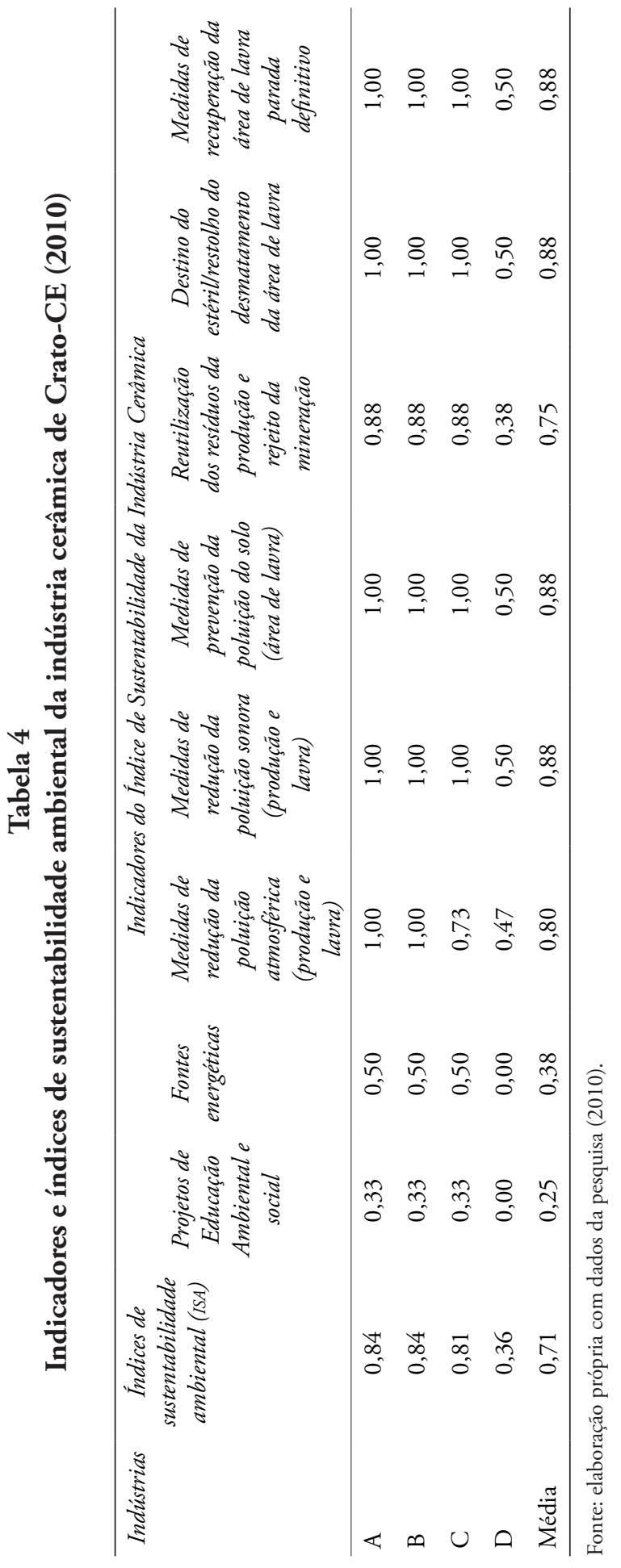




\subsection{Crescimento da indústria e as mudanças ocorridas na área de estudo: a percepção dos entrevistados}

O crescimento do setor cerâmico ensejou impressóes positivas e negativas na percepção dos entrevistados. Dos 165 pesquisados (comunidade e trabalhadores), $1 \%$ considerou esse crescimento negativo, $40 \%$ de forma negativa e positiva e $59 \%$ apenas como positivo.

Os pesquisados reconheceram que o crescimento do setor cerâmico produziu impactos que incidiram tanto sobre o meio ambiente físico quanto sobre os seres vivos que o compóem. Entre os impactos positivos mais relevantes foram apontados a geraçáo de emprego e renda e o desenvolvimento local do Município do Crato. Segundo 44\% dos entrevistados, as atividades ceramistas contribuíram para o desenvolvimento das comunidades. Os impactos negativos mais expressivos, na percepção dos entrevistados, foram a degradação do meio ambiente, a descaracterização da paisagem natural e a poluição atmosférica.

Quanto às mudanças ocorridas nas localidades, os trabalhadores que moram na área do estudo e a comunidade apontaram o aumento do número de residências, o crescimento da poluição atmosférica, a descaracterização da paisagem natural decorrente da retirada da vegetação e do solo pelas cerâmicas e o desaparecimento de espécies da fauna e flora, sendo os três primeiros os que mais se destacaram.

A maioria dos entrevistados não percebeu danos à agricultura ou à pecuária. Aqueles, porém, que consideraram as cerâmicas como responsáveis por prejudicar a agricultura apontaram como causas a falta de interesse das pessoas em trabalhar no campo, em razão de a cerâmica assegurar a renda, enquanto que a renda proveniente da agricultura é incerta, dependente das condiçóes ambientais e climáticas, sem falar que o trabalho no campo é "pesado" em relação a certas funções das cerâmicas; também, a substituição das áreas de plantio pela exploração mineral, uma vez que os donos das fábricas detêm boa parte das terras.

\subsection{Medidas de redução dos impactos gerados pela indústria de cerâmica vermelha}

Verificou-se que todas as indústrias possuíam fornos já adaptados com filtros (75\%) ou usavam filtros nas chaminés (25\%). Nem todas as cerâmicas, no entanto, reaproveitavam os gases da combustáo para secagem das peças, e as que reaproveitavam náo o faziam por todos os fornos. Setenta e cinco por cento das empresas disseram realizar o controle de gases emitidos para a atmosfera, embora nenhuma tenha informado a frequência com que o controle era feito. Uma empresa tinha projetos de 
redução de emissão de gases para a atmosfera em desenvolvimento, a saber: crédito de carbono e crédito de metano evitado. Duas outras empresas se encontravam em fase de elaboração de projeto de crédito de carbono. No que diz respeito à redução de gases provenientes das máquinas e caminhōes, as empresas mantêm uma manutenção periódica.

Apesar dos passos dados no sentido de minimizar os impactos e melhorar o processo produtivo, há necessidades de investir em uma produção mais limpa, otimizar o uso de combustíveis reaproveitáveis e a substituição de fornos com baixa eficiência energética por fornos que representem significativa economia de energia.

Como medida para reduzir a poluição atmosférica oriunda das áreas de mineração e dos galpóes de produção de cerâmica, $75 \%$ dos empresários responderam adotar a aguação dos galpóes e apenas $50 \%$ responderam fazer a aguação da área antes de iniciar o processo de lavra. As mesmas empresas que realizavam a aguação dos galpóes e da área a ser minerada empregavam, também, o mecanismo de barreira verde nas áreas de mineração para evitar a dispersão da poeira a longas distâncias, e cobriam as cargas de argila com lona, para evitar o derrame do material e, consequentemente, a poeira proveniente deste durante o transporte. Vale salientar que uma das quatro empresas não realizava processo de mineração, pois adquiria argila de terceiros.

Como forma de evitar a poluição do solo, a troca de óleo, a reposição de peças e o abastecimento das máquinas e caminhóes são feitos fora da área de lavra.

A manutenção periódica das máquinas e caminhôes usados na área de lavra e o uso de abafadores nas descargas das máquinas foram medidas utilizadas pelos ceramistas para diminuir o barulho proveniente dos veículos em funcionamento. Quanto à redução do barulho causado pelos equipamentos na área de produção, a medida adotada foi somente a de manutenção.

Além das ações ora mencionadas, como forma de reduzir os efeitos sobre os trabalhadores, os empresários ceramistas ofertaram os Equipamentos de Proteção Individual (EPI) previstos na Consolidação das Leis do Trabalho (CLT) e regulamentados pela NR6.

As medidas mencionadas de redução e prevenção dos impactos abrangem tanto o meio ambiente (fauna), quanto a comunidade do entorno e os trabalhadores das fábricas, exceto aquela referente à oferta de EPI, por ser um mecanismo de prevenção que visa a minimizar os impactos diretos na saúde do trabalhador. Esse conjunto de medidas pode ser compreendido, também, como uma forma de prevenção às doenças ocupacionais, conforme os Programas de Controle Médico de Saúde Ocupacional (PCMSO) e o de Prevenção de Riscos Ambientais (PPRA), que apontam, 
dentre outros agentes, a poeira, os gases e ruídos como capazes de causar danos à saúde dos trabalhadores, de acordo com (MT, 1978a; MT, 1978b).

Os moradores entrevistados foram unânimes em acentuar que o barulho proveniente das fábricas e das áreas de lavra não causava incômodo, em virtude de as residências se encontrarem às margens da Rodovia Estadual CE-055, e por aqueles estarem acostumados com o barulho do tráfego dos automóveis que por ali circulam diuturnamente.

A indústria cerâmica produz diferentes resíduos, notadamente os sólidos. É fato a perda de produtos cerâmicos acabados com defeitos (trinca, quebra e peças requeimadas). Também é fato, porém, o reaproveitamento desses resíduos, ora reincorporados ao processo produtivo, ora usados para recuperar áreas degradadas ou para aplainar terrenos. A literatura aponta as perdas no processo de fabricação de cerâmica em nível elevado, principalmente o prejuízo do produto acabado. Dentre os motivos estão a falta de critérios técnicos, de modernização tecnológica e de qualificação da mão de obra, fato este constatado por (Pessoa 2004; Nascimento, 2007). O percentual médio de perda por milheiro informado pelas cerâmicas cratenses foi de 3\% em uma indústria, $2 \%$ em duas e $1.30 \%$ em uma. Observou-se que a fábrica com maior percentual de perda de peças é também a menos desprovida de modernas tecnologias no seu processo produtivo, possuindo menor organização administrativa e poucos investimentos em qualidade e segurança no trabalho.

Durante a produção, as fases de conformação e secagem produzem resíduos sólidos, novamente incorporados ao processo produtivo, enquanto $50 \%$ dos resíduos de origem dos produtos acabados são usados para pavimentar áreas ao redor da indústria, 25\% para pavimentar área de extração mineral, $13 \%$ utilizados pelos governos municipal e estadual para pavimentar estradas carroçáveis e $12 \%$ para aterrar outras áreas.

A indústria de cerâmica vermelha, basicamente, se utiliza de água no processo produtivo (na hidratação da argila), mesmo assim em quantidade razoável, que evapora durante a queima. São gerados efluentes líquidos nas limpezas das máquinas, que ocorrem esporadicamente, não representando impacto expressivo.

Os ceramistas informaram que dão os seguintes destinos ao estéril ${ }^{1}$ oriundo do desmatamento da área de lavra e ao rejeito da mineração: ${ }^{2}$ o primeiro é estocado próximo à área de lavra, para posteriormente ser usado na sua recuperaçáo; o segundo é utilizado para aplainar a área de lavra, quando paralisada em definitivo, e doado.

\footnotetext{
${ }^{1}$ Entenda-se por estéril do desmatamento os restos de vegetais gerados após o desmatamento.

${ }^{2}$ Material inaproveitável retirado durante a extração mineral.
} 
Pode-se constatar que as empresas cerâmicas que realizavam extração mineral possuíam licenças junto aos órgãos competentes para a realização de tal atividade. Vinculados à licença, estáo o Plano de Controle Ambiental (PCA), que prevê medidas mitigadoras dos impactos ambientais, e o Plano de Recuperação de Área Degradada (PRAD), que determina a recuperação da área a ser minerada depois de paralisada em definitivo a exploração, sendo que ambos estấo previstos na Lei no 6.938/8, regulamentada pelo Decreto no 97.632/89. Para realizar esse tipo de atividade, devem ser observadas, também, as recomendaçóes das Normas Reguladoras de Mineração (NRM) constantes na Portaria no 237/2001, do Departamento Nacional de Produção Mineral (DNPM).

As medidas de recuperação da área adotada pelos empresários ceramistas participantes desse processo foram o aplainamento da área explorada e o reflorestamento com espécies dos tipos, cajueiro, angico, sabiá, catingueira, jurema, marmeleiro e palmeira.

Quanto a projetos sociais, $75 \%$ das empresas cerâmicas financiavam um ou mais de um tipo de projeto em escolas, creches, na Associação de Pais e Amigos dos Excepcionais (APAE) e abrigo de idosos. Havia, também, investimentos nos projetos de redução de emissão de gases para a atmosfera, segundo detalhado anteriormente.

\section{Consideraçóes finais}

Por intermédio de uma análise sistêmica, foi possível fazer a leitura do setor cerâmico de Crato sendo identificados fatores que ameaçam a sustentabilidade do setor: baixa qualificação de mão de obra visto que as indústrias cerâmicas do Crato apresentam mão de obra com pouca ou nenhuma qualificação (neste item inclui-se a necessidade premente de incentivo à melhoria do grau de escolaridade entre os trabalhadores); alta rotatividade de trabalhadores nas indústrias; o que pode dificultar o investimento na qualificação dessas pessoas e comprometer o bom desempenho da atividade ceramista; baixo nível tecnológico, emprego de técnicas e tecnologias ainda rudimentares, são aspectos predominantes embora tenha sido verificado que houve investimentos e aprimoramento do processo produtivo.

A indústria cerâmica é percebida pelos moradores das comunidades onde as fábricas estão instaladas e, também, por seus trabalhadores como fonte de emprego e renda, mas também como causadora de impactos ambientais que comprometem a qualidade de vida da regiáo.

Dentre os pontos negativos percebidos pelos entrevistados podem ser destacados a degradaçáo do meio ambiente causado pelo elevado consumo dos recursos naturais (argila e lenha), principalmente a argila, que é 
proveniente das áreas onde as cerâmicas estão instaladas, é decorrente da falta de planejamento sustentável dessa atividade à longo prazo; o aumento da poluição; a descaracterização da paisagem natural proporcionada pela expansão do setor.

Apesar dos impactos citados não terem sido comprovados empiricamente, o que não nos permite concluir sobre a sua real presença na área, o estudo sugere que os entrevistados têm consciência sobre a importância do meio ambiente e dos possíveis danos causados por uma indústria cerâmica não adaptada às tecnologias sustentáveis, ao mesmo tempo em que reconhecem a importância do setor para a geração de emprego, renda e melhoria da qualidade de vida das pessoas da regiâo.

As colocações feitas pelos empresários ceramistas por meio dos questionários e de conversas informais deixaram claro que esse setor é malvisto (entendido como depredador da natureza) pelos órgãos ambientais competentes nas esferas municipal, estadual e federal, que eles não veem essa atividade como geradora de emprego, renda e crescimento econômico; não oferecem suporte no sentido de ajudar e orientar os empresários nas questóes ambientais, apenas se preocupam em puni-los. Segundo os empresários, os órgãos ambientais não estão cumprindo o seu papel com eficiência, uma vez que os ceramistas alegaram demora nas renovaçóes e concessóes de licenças, o que os prejudica na aquisição de financiamentos junto a bancos, dificultando, assim, melhores investimentos no setor.

\section{Referências bibliográficas}

ABC (Associação Brasileira de Cerâmica) (2011), Informações técnicasdefinição e classificação, Informe da Associação Brasileira de Cerâmica, São Paulo, <http://www.abceram.org.br/site/index. php?area $=4>, 20$ outubro 2011.

Amaral Filho, Jair do e Kilmer Coelho Campos (2006), "Arranjo produtivo de cerâmica vermelha no município de Russas-CE”, relatório técnico, FINEP, Fortaleza.

Calvão, Teresa, Maria Fernanda Pessoa e Fernando Cebola Lidon (2013), "Impact of human activities on coastal vegetation--a review", Emirates Journal of Food and Agriculture, 25 (12), Al-Maqam United Arab Emirates University, Abu Dhabi, pp. 926-944.

Dias, Marilza do Carmo Oliveira, Mauri César Barbosa Pereira, Pedro Luiz Fuentes Dias e Jair Fernandes Virgínio (1999), Manual de 
impactos ambientais: orientaçôes básicas sobre aspectos ambientais atividades produtivas, Banco do Nordeste, Fortaleza.

FIEC (Federação das Indústrias do Estado do Ceará) (2005), "Setor cerâmico discute problemas e aponta soluções", Jornal da FIEC Online, Federação das Indústrias do Estado do Ceará, Fortaleza, $<$ http://www.fiec.org.br/publicacoes/jornalfiec/edicoes/1203/ default.asp?URL=4>, 23 setembro 2009

FIEC (Federação das Indústrias do Estado do Ceará) (2010), “O desafio da cerâmica sustentável”, Revista da FIEC Online, ano 4, ed. 38, Federação das Indústrias do Estado do Ceará, Fortaleza, <http:// www.fiec.org.br/portalv2/sites/revista/home.php?st=mais noticias\&conteudo_id=37776\&start_date=2010-07-20>, 13 dezembro 2010.

Gifford, Robert (2014), "Environmental psychology matters", Annual Review of Psychology, 65, Annual Reviews, Palo Alto, pp. 541-579.

Jacobi, Pedro (2003), "Educação ambiental, cidadania e sustentabilidade", cadernos de pesquisa n. 118, Fundação Carlos Chagas, São Paulo, pp. 189-205.

Leff, Henrique (2001), Saber ambiental: sustentabilidade, racionalidade, complexidade, poder, Vozes, Petrópolis.

Leite, Mariangela Garcia-Praça e Maria Augusta Gonçalves-Fujaco (2013), "A atividade de beneficiamento de quartzitos na cidade de Ouro Preto-Brasil: características gerais e principais impactos ambientais", Economia, Sociedady Territorio, XIII (41), El Colegio Mexiquense, A. C., Zinacantepec, pp. 227-243.

Maimon, Dália (1998), "Responsabilidade ambiental das empresas brasileiras: realidade ou discurso?”, in Clóvis Cavalcanti (coord.), Desenvolvimento e natureza: estudos para uma sociedade sustentável, Fundação Joaquim Nabuco, Recife, pp. 242-252NZZ.

MMA (Ministério do Meio Ambiente) (1981), Lei no . 6.938/81, Institui a Política Nacional do Meio Ambiente, Ministério do Meio Ambiente, Brasília, <http://www.mma.gov.br/estruturas/sqa_pnla/_arquivos/46_10112008050406.pdf>, 12 agosto 2012. 
MMA (Ministério do Meio Ambiente) (1986), Resolução no. 001/86. Avaliação de impacto ambiental, Ministério do Meio Ambiente, Brasília, <http://www.cati.sp.gov.br/Cati/_servicos/dcaa/legislacao_ambiental/Resolu\%C3\%A7\%C3\%A3o\%20CONAMA\%20 001_1986\%20\%20com\%20altera\%C3\%A7\%C3\%A3o\%20 Res\%20CONAMA\%20011_1986.pdf>, 10 agosto 2012.

MME (Ministério de Minas e Energia) (2010), Anuário Estatístico 2010: setor de transformação de não-metálicos, Secretaria de Geologia, Mineração e Transformação Mineral, Brasília, <http://www.mme. gov.br/sgm/galerias/arquivos/noticias/ANUxRIO_DA_TRANSFORMAxO_DOS_NxO_METxLICOS_-_2010.pdf>, 20 março 2011.

MT (Ministério do Trabalho) (1978a), NR7 - Programa de Controle Médico de Saúde Ocupacional, Ministério do Trabalho, Brasília, $<$ http://www.mte.gov.br/legislacao/normas_regulamentadoras/ nr_07_at.pdf>, 18 março 2011.

MT (Ministério do Trabalho) (1978b), NR9 - Programa de prevenção de riscos ambientais, Ministério do Trabalho, Brasília, <http://www. mte.gov.br/legislacao/normas_regulamentadoras/nr_09_at.pdf $>$, 18 março 2011.

Narasimha, C. y Nagesha, N. (2013), "Energy efficiency in sustainable development of small and medium enterprises: an empirical study", IEEE Xplore, IEEE, New York, 487-491 pp.

Nascimento, Waldécio Sávio dos Anjos do (2007), “Avaliação dos impactos ambientais gerados por uma indústria cerâmica típica da regiáo do Seridó/RN”, dissertação do mestrado em Engenharia Mecânica, Universidade Federal do Rio Grande do Norte, Natal.

OECD (Organization for Economic Cooperation and Development) (2001), "Environmental indicators, towards sustainable development", oecd Publications, Paris.

OECD (Organization for Economic Cooperation and Development) (2008), "Key environmental indicators", OECD Publications, Paris. 
Pessoa, José Manoel Albuquerque de Paula (2004), “Tecnologias e técnicas apropriadas para o desenvolvimento sustentável: o caso da indústria cerâmica de Russas-CE”, dissertação do mestrado em desenvolvimento e meio ambiente-Prodema, Universidade Federal do Ceará, Fortaleza.

PNUd (Programa das Naçóes Unidas para o Desenvolvimento) (2005), Relatório de desenvolvimento humano. Racismo, pobreza e violência, PNUd Brasil, São Paulo, <http://www.pnud.org.br/rdh/>, 7 julho 2010 .

Rodrigues, Maria Ivoneide Vital (2006), "Análise do plano de desenvolvimento sustentável do Estado do Ceará”, dissertação do mestrado em Economia Rural, Universidade Federal do Ceará, Fortaleza.

Rodrigues, Maria Ivoneide Vital, Patrícia Verônica Pinheiro Sales Lima, Maria Irles de Oliveira Mayorga e Francisco Casimiro Filho (2010), "Análise de impactos em áreas propensas à desertificação em municípios do Estado do Ceará", $2^{a}$ Conferência Internacional: clima, sustentabilidade e desenvolvimento em Regióes Semiáridas, ICID, 16-20 agosto, Fortaleza.

Rodriguez, Lucas Gutierrez e Manuel Ruiz Perez (2013), “Recent changes in chinese forestry seen through the lens of Forest Transition theory", International Forestry Review, 15 (4), Commonwealth Forestry Association, Shropshire, pp. 456-470.

Sánchez, Luis Enrique (2008), Avaliação de impactos ambientais: conceitos e métodos, Oficina de Textos, São Paulo.

Tommasi, Luiz Roberto (1994), Estudo de impacto ambiental, CETESBTerragraph Artes e Informática, São Paulo.

Van Gemert, Frederik, Niels Chavannes, Nahid Nabadda, Simon Luzige, Bruce Kirenga, Celeste Eggermont, Corina de Jong e Thys van der Molen (2013), "Impact of chronic respiratory symptoms in a rural area of sub-Saharan Africa: an in-depth qualitative study in the Masindi district of Uganda", Primary Care Respiratory Journal, 22 (3), Elsevier, Amsterdam, pp. 300-305. 
Recibido: 3 de octubre de 2012. Reenviado: 12 de julio de 2013. Aceptado: 4 de febrero de 2014.

Zoraia Úrsula Silva de Alencar-Linard. Brasileira. É mestre em Desenvolvimento e Meio Ambiente pela Universidade Federal do Ceará-UfC, Brasil. Atualmente é professora da Rede Municipal de Ensino de Fortaleza-CE. Sua linha de investigação é desenvolvimento e meio ambiente. Entre suas últimas publicações destacam-se, em co-autoria, "Educação ambiental e sua contribuição para o meio ambiente e a indústria de cerâmica vermelha”, em Kelma Socorro Alves Lopes de Matos (org.), Educação ambiental e sustentabilidade II, Ediçóes UFC, Fortaleza, pp.137-149 (2010); en co-autoria, "Educação para o desenvolvimento sustentável e educação ambiental”, Conexão, Ciência e Tecnologia, 5 (1), Instituto Federal Ceará, Fortaleza, pp. 25-31 (2011).

Ahmad Saeed-Khan. Brasileiro. É Ph.D. em Economia Agrícola. Atualmente é professor do Departamento de Economia Agrícola, Centro de Ciências Agrárias da Universidade Federal do Ceará. Professor do Programa de Pós-Graduação em Economia Rural e do Programa de Pós-Graduação em Desenvolvimento e Meio Ambiente (Prodema) da UfC. É Pesquisador do CNPq. Conselho Nacional de Desenvolvimento Científico e Tecnológico, nível 1A. Sua linha de investigação é Avaliação de Políticas Públicas, Desenvolvimento Rural, Desenvolvimento e Meio Ambiente. Entre suas últimas publicaçôes destacam-se, em co-autoria, "Nível tecnológico e emissão de poluentes: uma análise empírica a partir da Curva de Kuznets Ambiental", Revista de Economia Aplicada, 17 (1), Universidade de São Paulo, Ribeirão Preto, pp. 21-47 (2013); "Relacionamento de preços dos principais produos comercializados entre o mercado produtor de tingaua e mercados atacadistas de Fortaleza e Teresina", Revista Econômica do Nordeste, 43, Banco do Nordeste, Fortaleza, pp. 171-185 (2012); "O impacto do Pronaf sobre a sustentabilidade da agricultura familiar, geraçấo de emprgo e renda no estado do Ceará”, revista de Economia e Sociologia Rural (Impresso), 49, Editora Atomo, Brasilía, pp. 129-156 (2011); "O Impacto do Programa Agente Rural sobre a qualidade de vida e geração de emprego e renda das famílias assistidas do estado do Ceará", Revista Econômica do Nordeste, 42, Banco do Nordeste, Fortaleza, pp. 425442 (2011).

Patrícia Verônica Pinheiro-SalesLima. Brasileira. É doutora em Economia Aplicada pela Escola Superior de Agricultura Luiz de Queiroz, Universidade de São Paulo. Atualmente é professora do Departamento de 
Economia Agrícola, Centro de Ciências Agrárias da Universidade Federal do Ceará. Professora do Programa de Pós-Graduação em Economia Rural e do Programa de Pós-Graduação em Desenvolvimento e Meio Ambiente (Prodema) da UfC. É Pesquisadora do CNPq, Conselho Nacional de Desenvolvimento Científico e Tecnológico, nível 2. Sua linha de investigação é Indicadores de sustentabilidade, Desenvolvimento Rural, Desenvolvimento e Meio Ambiente. Entre suas últimas publicaçóes destacam-se, em co-autoria, "Nivel tecnológico e emissão de poluentes: uma análise empirica a partir da Curva de Kuznets Ambiental”, Revista de Economia Aplicada, 17 (1), Universidade de São Paulo, Ribeirão Preto, pp. 21-47 (2013), "Caracterização do Comércio da CEASA - Ceará", Revista Perspectiva Online: Humanas \& Sociais Aplicadas, 2 (4), Institutos Superiores de Ensino do CENSA, Campos dos Goitacazes, pp. 1-11 (2012); "O impacto do Pronaf sobre a sustentabilidade da agricultura familiar, geração de emprgo e renda no Estado do Ceará”, Revista de Economia e Sociologia Rural, v. 49, Sociedad Brasileña de Economía y Sociología Rural, Brasilía, pp. 129-156 (2011); "Políticas públicas e desenvolvimento sustentável: a realidade dos assentamentos de reforma agrária no Ceará”, Revista de Politicas Públicas, 15, Universidade Federale do Maranhão, Maranhão, pp. 85-97 (2011). 